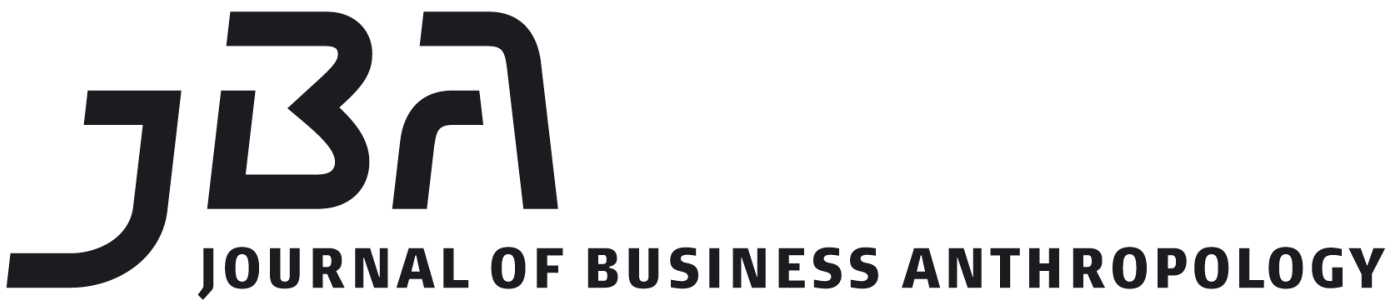

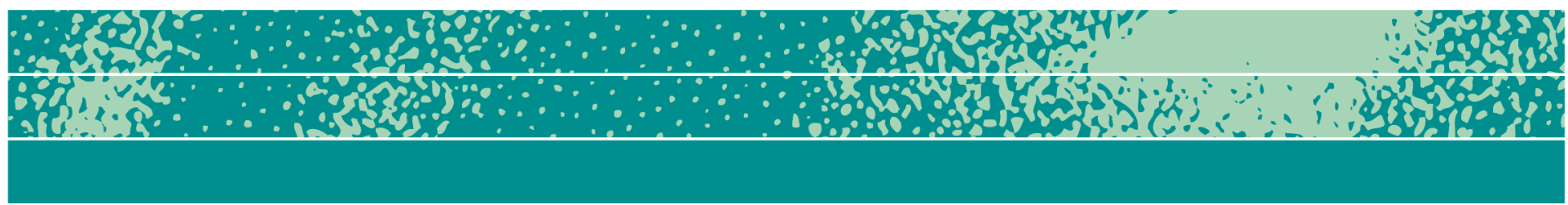

\section{The Use of Anthropology as a Management Framework in a Corporate Context: Review and Prospects}

Kevin Preister

\begin{abstract}
Many anthropologists work with corporations to understand and work effectively with communities impacted by their activities. This paper presents a Social Ecology model oriented to citizen empowerment and impact management, identifying concepts that shape ethnography into a management framework: informal networks and routines, human geography, and citizen issue management. Affecting corporate behavior can be accomplished in phases, from community assessment, to issue management, to ethnographic training programs. Their applications are described in a subdivision development, an electric utility project, and a program of paradigm change in the right-of-way, infrastructure and energy industries.
\end{abstract}

\section{Keywords}

social ecology, issue management, human geography, discovery process, citizen empowerment
Page 1 of 23

JBA 7(1): 75-97

Spring 2018

(C) The Author(s) 2018 ISSN 2245-4217

www.cbs.dk/jba 


\section{Introduction}

As anthropologists rapidly move into the world of design in different business settings, it is wise to remember the long history of anthropologists working with business interests in economic and community development settings. Anthropologists have been concerned with ecological impacts (social, cultural, economic, physical and biological) of corporate activities and have been active in research, advocacy and policy work for many decades. In this paper, I am interested in how ethnography can be shaped in a framework that is more directly useful for corporate management and policy.

This focus is especially germane to the trends affecting business today:

- Increased globalization with attendant increase in diversity of worker and customer base;

- The growth of policy related to Corporate Social Responsibility (CSR-German companies are now being asked to report on outcomes of their CSR policies);

- The growth of state directives to manage impacts of change (such as China's 18 $8^{\text {th }}$ Party Congress in 2012 that ordered all major industrial projects to complete a "social risk assessment" along with impact mitigation schedules before any new project can begin);

- Increased scrutiny of corporate activity worldwide; and,

- The growth of social media that allows rapid citizen communication and mobilization around resistance to unwanted initiatives through boycotts or in support of initiatives.

In short, community goodwill is becoming an ever more precious resource, hard to gain and easy to lose, by which companies have to measure their bottom line. These dynamics create openings for the skills of anthropologists.

In this paper, I describe my experience in the use of anthropology as a management framework oriented to assisting corporations (and governments) understand and work with communities in dealing with the effects of change. Elsewhere I have defined the "best" of applied anthropology as:

"the varied means used by anthropologists to foster social change by working within the existing social systems of a culturallydefined, geographically-based local community. It is a process of facilitating reflection and action within everyday routines through which individuals become conscious of their environment so that they can empower themselves to act upon it for survival, caretaking and maintaining culture" (Preister 2010: 25) 
In this paradigm of implementation practice, the anthropologist as a manager of change projects identifies not as a researcher but as a reflective change agent. Can real-time description of how a community is currently functioning, and an assessment of citizen-identified issues and opportunities, present a resource in assisting companies to be aware of and responsive to the impacts they create? This paper is devoted to a positive response.

Outlined below are three ways in which ethnography is shaped to be useful in a management framework. I will use this conceptual scheme to describe through stories three phases of effort in which understanding of community has been fostered with corporate clients, namely, community assessment, issue management, and cultural-based training programs.

I operate through two companies, a for-profit company called James Kent Associates (JKA) which is a consultant company serving business and government, and the Center for Social Ecology and Public Policy (CSEPP), a non-profit corporation, of which I am the Executive Director. We encourage our clients to "learn community first" before announcing a new project, program or policy, identify the ways in which community interests can be addressed through the design and implementation of the change initiative, and to be systematic in optimizing local benefits. In this way, the change can be absorbed into the community and become an extension of it, rather than be experienced as an impacting force of intrusion and disruption. Let's see how this perspective has been promoted and exercised.

\section{Tenets of social ecology}

The heart of ecological understanding is description of the relations between life forms in a specific locale. So too with social ecology. Social Ecology seeks first to understand how humans relate with each other in place-based geographic settings, and how they relate with the physical environment, life forms, and resources around them. It then seeks to foster action on that understanding in ways that promote "productive harmony", as called for by the National Environmental Policy Act (NEPA) - that balance between humans and nature that fosters sustainability (Preister and Kent 2001). We want to understand the norms and the cultural mechanisms by which these relationships are mediated so that a corporate change initiative can fit within and contribute to the existing social system as part of its success.

Social Ecology is a scientific enterprise of understanding community and the forces that affect community. Our term for implementing a social ecological approach is called the "Discovery 
Process," an empowerment methodology that builds citizen and institutional capacity for creating and enhancing healthy environments. These definitions are cogent:

Power

Citizen Issue

Management

Concern

Cultural Alignment
The ability of an individual to participate in, predict and control changes in his or her environment without oppressing others. We make use of Freire's dialectic of action and reflection to foster individual empowerment (1970).

A statement made by members of informal networks in response to a proposed change initiative that is specific enough that it can be acted upon.

A statement made by members of formal organizations in response to a proposed change initiative that is specific enough that it can be acted upon.

The integration of citizen issues (arising from informal networks operating for survival, caretaking and cultural maintenance) and management concerns (arising from vertical, formal organizations oriented to political, economic or ideological control) into a management system that serves both sets of interests. It is a method of fostering sustainability in a community, corporate and government ecosystem.

Human Geographic The natural borders at different geographic Units scales defined by people in a specific area to distinguish one population from another.

There are three sets of concepts that enable anthropology to be shaped into a management framework that facilitates responsive corporate management practices. Each of the three will be discussed in turn:

1. A descriptive approach to community to identify informal 
networks and local routines as action elements;

2. Human geography and the natural boundaries of the people in a geographic area of impact; and

3. Citizen issues identification and resolution as a management framework.

\section{Concept one: A descriptive approach to community}

A descriptive approach is a real time account of how people in a community currently function-who talks with whom, who doesn't talk with whom, who is well-regarded or revered, how people currently manage change, and the cultural mechanisms in place by which change is absorbed.

Description is "just the facts," as Franz Boas used to emphasize. John Steinbeck (1941) called this process the "science of 'What is?'”, to simply describe the who, what, why, where, and when of human interaction in a community setting. Steinbeck was a master at describing informal networks and their survival functions and we consider him the first social ecologist (Kent 2014). Informal networks and caretaking systems form the social capital by which communities sustain themselves. Every community (and organization) has informal systems of communication and support by which people survive and take care of each other. Moreover, communities have formal systems of elected political leaders, organizations, and businesses that are vertical in their structure and operate through a hierarchical ordering of authority relationships, technical knowledge, and organizational routines.

Figure One shows the way that CSEPP describes social organization for corporate clients. They generally understand the vertical world of organizations, with elected or appointed leaders, organizational goals, membership lists, formal communication, and use of formalized meetings and scheduled times. Less well understood in the corporate world is the horizontal system of informal networks in communities in which members support each other in ongoing and predictable ways. That world is governed by respected leaders, flexible goals, informal recognition of members, and the use of gathering places and natural routines. The anthropologist's job is to make the informal system visible so it becomes a resource to foster responsive management practices.

Instead of operating through meetings, the informal system works through gathering places and the routine sharing of information. Gathering places are key social institutions where, even in the age of social media, people rely on face-to-face communication with people they trust in order to solve the challenges of everyday living (Oldenburg 1989). Gathering places are the locations at which people develop their public positions about proposed projects. Part of the management framework is 
to assist corporate clients to be part of this communication system so that information about what is being proposed is usable by the citizens and they can evaluate its benefits.

Describing and accessing networks also reveals network archetypes, those recurring "jobs" within networks that promote their ongoing operation. The eight archetypes we have regularly observed in informal networks are caretaker, communicator, storyteller, bridger, opportunist, gatekeeper, historian and authenticator (Malone 2007). Of these archetypes, caretakers and communicators are the most wellregarded in their social circles and by definition have high social standing. These individuals typically are not political and have no agendas beyond their mission of taking care of people in their networks and sharing information about the latest. They are steeped in the cultural language important to their peers and can assist a project team to stay grounded in local interests. They are the ones that can dampen the influence of the more extreme voices that typically dominate in a controversial project. They are key to developing a "moderate middle."

Figure One also reveals the sociological function of the two forms of citizen organization. For the vertical world, the sociological function is political, economic and ideological control, given impetus by the industrial revolution and the need of society to manage mass production and consumption. The plethora of formal organizations exerting influence on our lives is one of the fundamentals of modern life. On the other hand, the informal system functions to provide caretaking, survival and the maintenance of cultural values. This system holds the culture of the community and the meaning of social life for participants. Knowledge of how people take care of each other, their adaptive strategies for survival, and their strong attachment to cultural beliefs and practices offer an outside corporate representative an opportunity to be an insider to the culture and thereby be able to freely discuss how the corporate project will affect citizens and offer a benefit. 


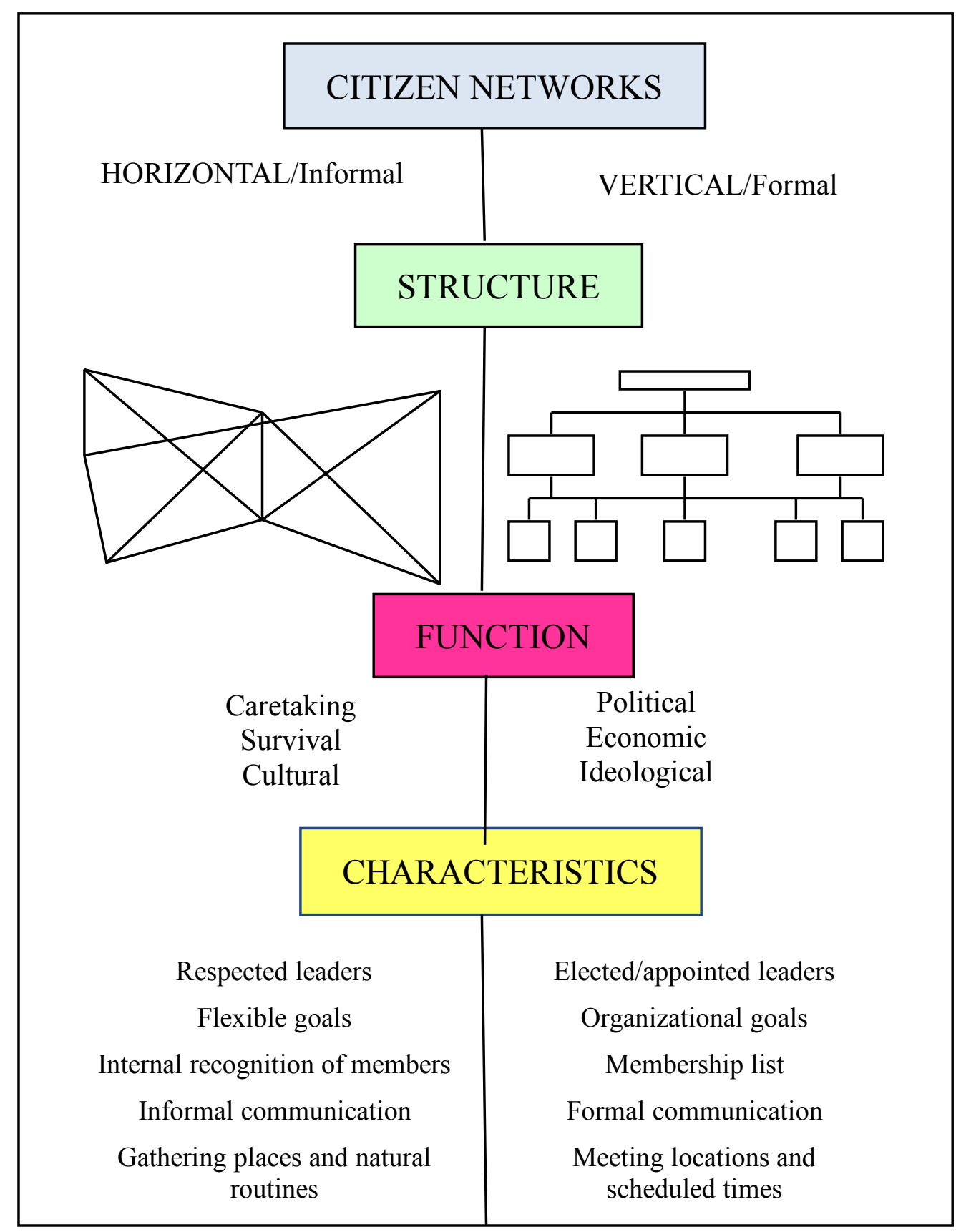

C 2017 CSEPP, Inc., all rights reserved

Figure 1. Forms of Social Organization 
It is easy to see with this conception of society that in situations of an oppressive formal system, or in very rural areas where services are in short supply, that the informal system must be strong in order for society to survive. In situations where the formal system is effective and efficient, say a stereotypical suburb with traditional wage earners, the informal system may be attenuated in which people do not know their neighbors and there are fewer occasions for mutual communication and action.

In our management framework, a sustainable society is fostered when both horizontal and vertical worlds are aligned. While the formal system often has the legal authority, technical expertise and budget to implement change projects, it is often ignorant about how people actually live in communities and survive in everyday life. They do not know the culture, so citizen behavior often seems irrational or incomprehensible. When we worked with the Environmental Protection Agency years ago on a lead-filled Superfund site, its officials could not understand why parents did not seem to want to test their children for lead poisoning. They did not understand that the way they entered the community so angered people that their health-seeking behavior went underground, not to be shared with the enemy (Hunka et.al. 1997). When people in the formal system have capacity to understand the informal system and incorporate the interests of the networks, opportunities for alignment are many.

\section{Concept two: human geography}

Human Geography is the second concept that helps position a company to be proactive around community interests. People everywhere develop an attachment to a geographic place, characterized by a set of natural boundaries created by physical, biological, social, cultural and economic systems. Unique beliefs, traditions, and stories tie people to a specific place, to the land, and to social/kinship networks, the reflection and function of which is called culture.

Social and cultural systems have been mapped by our companies for over 40 years. The first Human Geographic Maps (HGMs) came into existence in the late 1970s and early 1980s as part of our work with the forest planning process of the U.S. Forest Service, Region 2. The USFS was looking for new and creative ways to empower citizens as part of the Forest Plans. The HGMs were published as an integral part of the Forest Plan implementation. This was followed in 1986 by a contract with the US West (now Century Link) Corporation to socially map the 14 western states of the U.S. that made up their service area in order to launch their cell phone business based on cultural word-of-mouth and natural boundary systems. Subsequently the HGMs have been used by 
communities, businesses, corporations, governments and citizens to improve relationships, make trend projections, develop market segments, and to understand emerging patterns in order to change the way government and business is conducted. In 2000, the Bureau of Land Management (BLM) of the Department of Interior entered into a thirtyyear license agreement with JKA to digitally produce the Human Geographic Maps and to use them in planning and management within BLM district offices. To date, about 15 BLM officers have made active use of the mapping process and products.

Operating at the proper scale brings optimum efficiency and productivity to projects, programs, marketing, policy formation and other actions by working within the appropriate social and cultural context (Kent and Preister 2011). Six different scales of cultural or human geography have been discovered which have been successfully applied to program and policy development, ranging from the neighborhood, community and regional level up to the global level.

The HGMs represent the culture of a geographic area, especially the informal systems through which people adapt to changes in their environment, take care of each other, and sustain their values and lifestyles. The HGMs represent the boundaries within which people already mobilize to meet life's challenges. Hence, their experiences are used through their participation as place-based knowledge to create ownership in issue resolution, project planning and implementation, public participation, and public policy development.

Figure Two below provides a sample human geographic map showing the Four Corners region of the U.S. in which the confluence of four states provides a unique cultural setting. The map shows two of the six scales of human geography. Human Resource Units (HRUs) are roughly equivalent in size to a county but seldom correspond to county boundaries. HRU boundaries are derived from seven Cultural Descriptors: settlement patterns, publics, networks, work routines, support services, recreational activities and geographic features (Kent and Preister 1999).

HRUs are characterized by frequent and customary interaction. Face-to-face human society is important at this scale of human geography, within which people have personal knowledge of each other and welldeveloped caretaking systems sustained through informal network relationships. People's daily activities occur primarily within their HRU including work, school, shopping, social activities and recreation. Health, education, welfare and other public service activities are highly organized at this level with a town or community almost always as its focal point. HRUs are most useful at the program level as they reveal widespread human routines that can easily be responded to in program development.

Social Resource Units (SRUs) are the aggregation of' HRUs on the basis of geographic features of the landscape, often a river basin, for 
example, or a geologic province, and they represent the basis of shared history, lifestyle, livelihood, and outlook. At this scale, face-to-face knowledge is much reduced. Rather, social ties are created by action around issues that transcend the smaller HRUs and by invoking common values ("We love the high desert.").

SRUs are characterized by a sense of belonging. These are rather large areas and one's perception as to the Unit's boundary is that when you cross the SRU boundary you are in an entirely different culture. There is a general feeling of "oneness" as being a part of this regional Unit. There is a general understanding and agreement on beliefs, traditions, stories and the attributes of being a part of the Unit. SRUs are useful at the policy level because of their regional orientation.

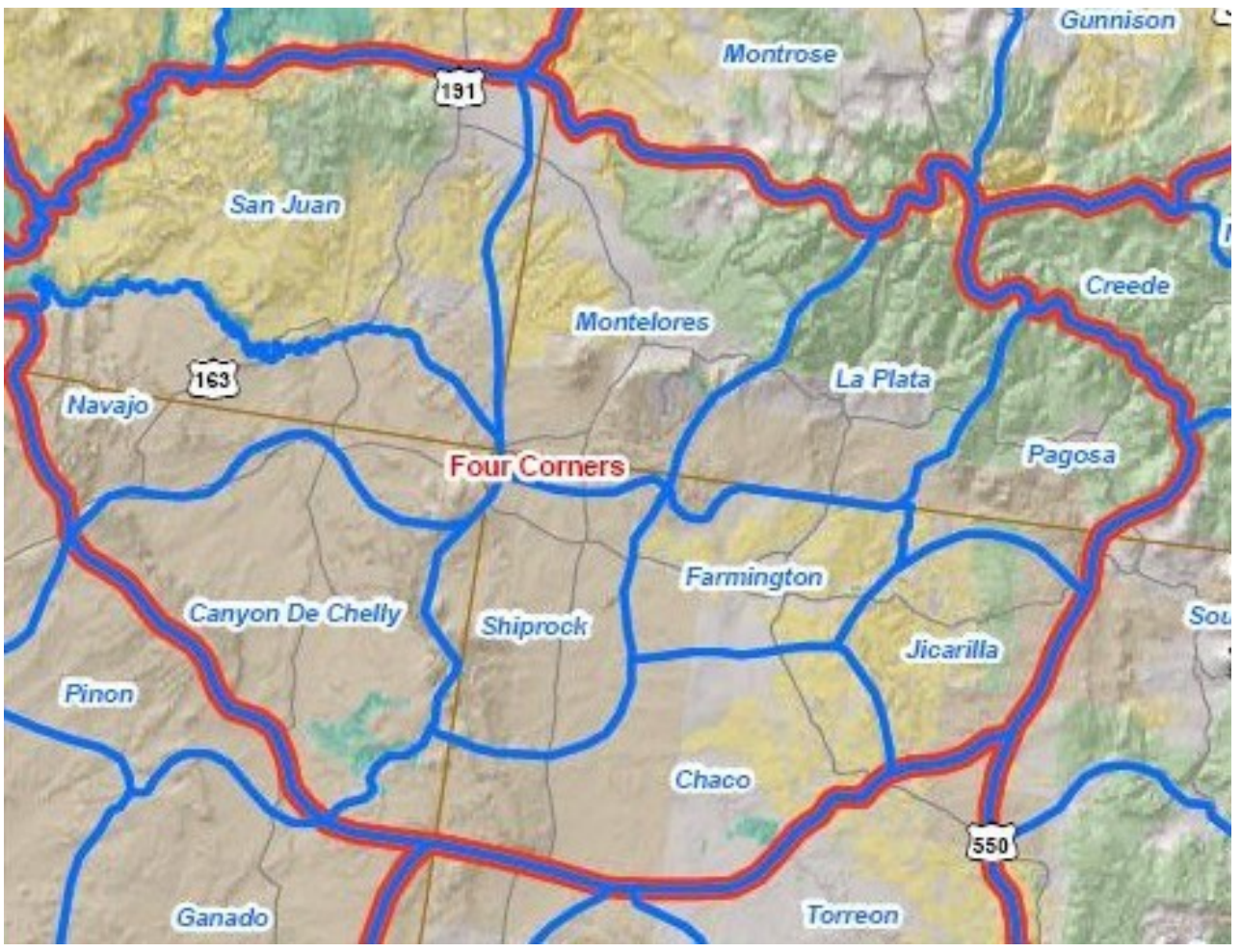

(C) 2017 CSEPP, Inc., all rights reserved

Figure 2. The Four Corners Social Resource Unit (SRU) with its Embedded Human Resource Units (HRUs)

\section{Concept three: issue management}

Issue Management is the ability of an organization to identify three stages of issues--emerging, existing, and disruptive--and to respond to them in timely, culturally-appropriate, and effective ways. Emerging issues are a curiosity phase, an existing issue is a demand for change, and a disruptive issue leaves the ability of a company to resolve and is handled in the courts or legislatures. This three part scheme has the advantage of justifying an ethnographic approach because emerging issues by their nature are not very visible. They are held at the network level, thus 
requiring contact at the informal level of society. Most citizen issues experienced at public meetings or hearings are already at the existing or disruptive stages, subjecting the meeting holders to the anger of alreadyfrustrated people. This is not a situation conducive to productive resolution of issues. Rather, we gain access for our clients to informal networks in order to foster meaningful discussion.

A citizen issue has to have a name and a face associated with it to keep the management process grounded. All too often, after "input" is received, the so-called "experts" will take over and want to figure out the solution, depriving the issue holder of participating in the resolution and short-circuiting the empowerment process. An issue also has to be actionable. If someone says, "I'm against growth," we call that a community theme because it is a statement that you can hear many times while conducting fieldwork, it will be reinforced in social life as heads nod and others voice their agreement, but it is too abstract to take action on. However, if someone says, "I'm against growth because the parks are overcrowded and my kids have no place to play," that is actionable. We can shape development to have parks or take other measures to address the issue. Often times in public discourse, community themes can dominate the dialogue, making it difficult to find out what the real issues are. Sometimes themes are used deliberately to advance a political agenda ("The company is going to destroy our community-it's only interested in profits.").

In operating an Issue Management program, we ask our corporate clients to develop communication and action opportunities that will respond to both citizen issues of the grassroots but also to the management concerns of the company and other formal organizations. What actions can resolve, or at least make progress, on both sets of interests? A few years ago, in a workshop in Socorro, New Mexico, a Bureau of Reclamation official stood up and said, "I've got one for you. I have a recreational bulldozer who wants to come on public land and move dirt around." Everyone laughed when he said this and the quick assumption was that the person was off the edge and could be promptly ignored. But one participant remembered that the Bureau of Land Management people had talked about all the gravel pits they had authorized on the middle stretch of the Rio Grande River and that they had to find a way to re-distribute the streambed material. Voilà! A single action resolves both a citizen issue and a management concern.

When cultural alignment is achieved, that is, when citizen issues in the community are integrated with the management concerns of institutions, the capacity of both informal and formal systems are enhanced in creating a healthy and sustainable environment. Figure Three offers a graphic display of community description and issue management. 
If ethnography is shaped around real-time description, human geography and the actionable issues of affected citizens, it is more useful to policy and decision-makers than traditional ethnographies. By presenting ethnography in a management framework, anthropologists avoid being relegated to the public relations department and instead get access to decision-makers.

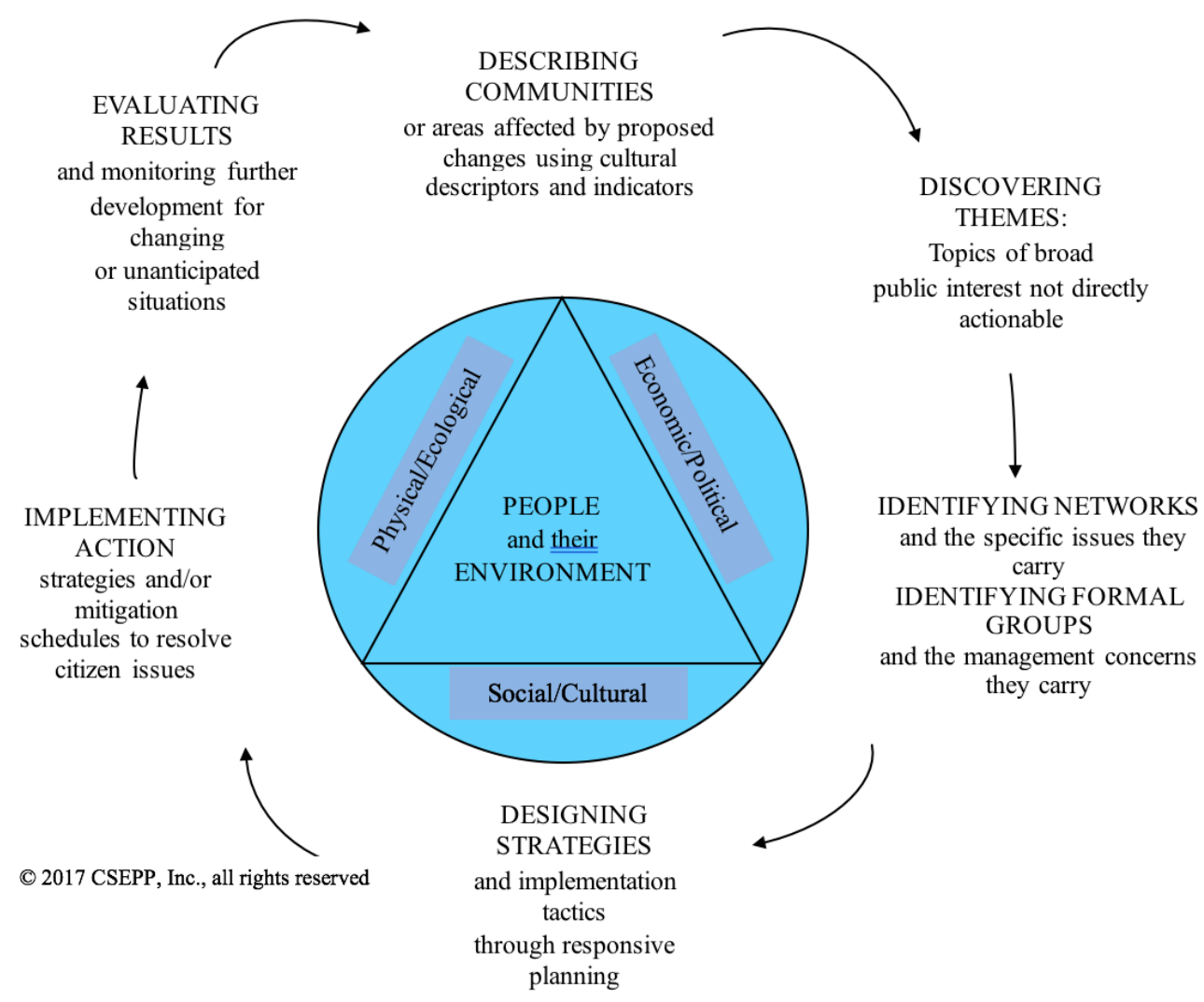

Figure 3. The Discovery Process as Strategy for Action

\section{Case examples of three phases to influence corporate decision- making}

Social Ecology is a robust theory of how social change works and it provides a methodology for facilitating social change over time (Preister 2014). Through the case examples below, I show how there can be phases by which anthropologists can influence corporate decision-making. The first phase is community assessment, a look at "what is" at the present moment in terms of how the community and the corporation are functioning, and the history and current status of change projects. A second phase entails citizen-based issue management to resolve with residents their issues while also resolving management concerns of the organization, seeking to improve project design and implementation. This is a process of cultural alignment. A third phase is the creation of training programs in social ecology shaped into a management framework for 
promoting ongoing decisions that are socially-responsive. Under some conditions, this work leads to an additional phase of policy development at the corporate level.

Well over half of our company projects end after the descriptive phase. We believe that any corporation or government unit should be able to learn what people are saying, without necessarily expecting organizational change. Not all corporations or government units want to follow-up on Phase One information for a variety of reasons. However, if a company agrees to go beyond Phase One, it is fair to expect some level of accountability on its part. Sometimes companies want to put us into a "public relations" box and believe it is our job to talk citizens into supporting the project. It is not. It is our responsibility to obtain for our client a fair understanding on the part of citizens of what the project entails, how it will affect them, citizen ideas for improving the design and implementation of the project, and fostering good communication between the parties.

Generally, the longer anthropologists stay involved, the greater the opportunities for promoting positive social change locally. Over the years we have mixed funding strategies for staying involved if opportunities are present for making a difference. For instance, Vail Associates supported our work in the 1970s to help manage the impacts created by the rapid expansion of the ski industry in Colorado, but when its own goals were achieved, its interest waned. We found foundations to support workforce development projects and helped residents begin 38 minority-owned businesses (Preister and Kent 2001).

The case examples I will review are the Two Rivers Village, Holy Cross Energy and the International Right of Way Association, Inc., illustrating each of the phases of community assessment, issue management, and training programs respectively.

\section{Community assessment: the Two Rivers Village story}

JKA worked with Two Rivers Village (TRV) Inc. to address weak home sales in its subdivision. TRV was approved near the town of Dotsero, Colorado for a total of 433 single-family and townhouse units on land contiguous with the Colorado and Eagle Rivers and their confluence, with three lakes, and amenities such as a clubhouse, swimming pool, soccer field, and basketball court. The units are manufactured houses available for Federal Housing Authority financing. In 2004, only 32 units had been assembled and 17 units had been sold with families living in them, indicating a weak market position. JKA was hired to conduct a situational assessment of the Eagle Valley market area, and to recommend a set of strategies that would help effectively re-position Two Rivers Village in the marketplace so that its sales and its contributions to community life would be increased. 
Our team, made up of anthropologists and anthropologicallytrained fieldworkers, attended public events and gathering places in the area, got invited to people's homes, and interviewed banking, government, financing, and alternative housing officials. We asked people what drew them to this area, what makes them stay, and what would make life better. We asked how people define quality of life in the valley, what their commutes are like, and how they make ends meet. We asked specifically about housing needs, their experiences as renters and buyers, what they look for in a house and in a community. Importantly, we kept asking, "Who else should we talk to about this?" so that we could continue to widen our connections into the community.

We found:

- Awareness of the project outside the closest communities was not high.

- Some residents had high expectation of purchasing a home at Two Rivers, particularly residents of the mobile home parks in the region and especially Hispanics in one particular mobile home park who had come from Chihuahua, Mexico.

- Resources that could assist in the process of "first time home ownership" were not being utilized.

- The project was disconnected from its most likely customers, especially Hispanics, and the project team was not building relationships in these communities.

- The subdivision was socially-isolated from community life, recreation activity and public events. The company official that supervised the sporting complexes, particularly a coveted soccer field, would not allow outside groups to use the facilities.

- Project managers had few ties with local residents.

- From the beginning of the recreation economy in Vail in 1962, residents have noted the cultural boundary that separates the highland recreation area of the Upper Eagle Valley from the drier and lower elevations of the Lower Eagle Valley to the west. As the recreation economy moved west, so did the invisible line by which people have said, "That's too far!" One woman related that when she moved to East Vail in 1973 and told someone she was going to Edwards, the friend remarked, "Way down there?" But now Edwards is part of the upper valley recreation economy. Similarly, Gypsum, a few miles further west, a few short years ago was considered "too far," but now workers routinely commute from Gypsum to their recreation jobs "up" the valley.

In response to the broad disconnect between Eagle County communities and Two Rivers Village, a deliberate effort to create 
"community" within the project was begun. Through the coaching by residents of the JKA team, we learned that there were many local activities and events that could be staged at Two Rivers Village, such as youth programs, soccer tournaments and leagues, fishing, a put-in point at the river, sports events, soccer camps, Wild West Day and basketball. The idea was that more people would be on site, and excitement would be generated about the project.

In addition, our team found several residential areas in which people were actively seeking other housing opportunities but were stymied for a variety of reasons, such as mobile home owners who did not know how to dispose of their trailers and people who were in position for first time home-buying but did not know the resources available to make it happen. Moreover, we found among Hispanic residents a keen interest in Two Rivers Village as an ideal stepping stone for their housing aspirations but who needed pathways for making their dreams come true.

Officials at Two Rivers Village responded enthusiastically to ideas we generated, dispatching Spanish speakers to the right locations, directing their recreation people to encourage community use of their facilities, and educating themselves as to the resources for first time home-buyers in the county. A key decision was to settle a Federal Express worker into the community. The logic was that he had a large informal network of individuals and families and if he settled in Two Rivers others would follow as he told stories about living there. He told the stories and several members of his networks came to Two Rivers to live (Preister et.al. 2004).

\section{Issue management: the Holy Cross Energy story}

Holy Cross Energy is a small, nonprofit electrical cooperative serving five counties in Western Colorado. In 2002, it determined that it could no longer avoid dealing with worsening reliability issues and it had to build a substation and a transmission line in the Snowmass area of the Roaring Fork Valley, near Aspen, Colorado. Holy Cross could have used the power of the Public Utility Commission to obtain a favorable ruling but believed that approach would harm the company and its reputation for positive community relationships. It wanted a non-confrontational approach.

It contracted with JKA to develop an issue management program. Our work was complicated by political feuding between two jurisdictions which would have to sign off on the project, Pitkin County and Snowmass Village. Moreover, a current proposal to bring in a million square feet of commercial and retail space to Snowmass Village had polarized the valley and had left feelings raw. We could not afford to have the Holy Cross project be contaminated by either of these two risks.

As JKA got into the community, residents told stories of how they 
came to live in the valley, what was important, why they stayed, and the elements of community life they found valuable. One strong value expressed was fairness. "I don't want my neighbors subject to a corridor I would not want myself," one person said. People were proud that they took care of each other in the communities. We also learned that residents had a passion for facts. As a wealthier professional community, there were many retired people with extensive background in technical issues and in project development. In the chat sessions we would have in people's homes, there would always be someone with a calculator checking out the numbers. We had "citizen-based mathematicians!" We began to elicit the assistance of these individuals who helped the project in various ways. They helped determine the surcharge boundary by knowing who would benefit and who would be impacted, thus avoiding a rate payer battle. A central interest was to bury the lines to protect the visual integrity of the area. These individuals figured out a surcharge that would be socially-acceptable to the community. Citizens had been saying that a $20 \%$ surcharge was a breaking point but that $15 \%$ was tolerable. Holy Cross analysts determined that they could come in under the $15 \%$ number and in fact they made it work at $11 \%$.

The outcome: instead of an air cooled system, a Gas Insulating System from Europe was imported which required $8500 \mathrm{SF}$ instead of $88,000 \mathrm{SF}$ (two acres). The final product looks like a barn on a small rural road. For the company, citizens changed from potentially-scary enemies to allies. The president of Holy Cross was quoted in public saying our company had saved him $\$ 10$ million and he still wasn't sure how we did it.

\section{Social ecology training program: The International Right of Way Association (IRWA) story}

Witness these events: the takeover of a public parkin Turkey to build a shopping mall; the raising of the public bus fare in Brazil; the government closing Greece's major newspaper; the high level of public protest regarding the Keystone XL pipeline proposal; and the almost instantaneous social movement fostered by the Standing Rock Sioux to forestall the Dakota Access pipeline. What do these events have in common? The authorities in these situations made a decision to impose a project solution without talking with the people who would be affected by the decision.

The Turkish governmentdecided to take over a small public park to build a shopping mallwithout seeking input/feedback from the community. In Brazil, raising the bus fares (mostly affecting poor people) seemed to be a reasonable approach to raise revenues for the 2016 Summer Olympic Games. In Greece, the shutdown of the government newspaper and the firing of a couple of dozen workers were done to demonstrate austerity to the European Union. In the United States, the route of the Keystone pipeline, 
proposed to carry tar sand oil from Alberta, Canada, to Houston for refining, was planned to run across Nebraska's Ogallala aquifer and through the Sandhills, which are sacred cultural icons in that region (Kent and Preister 2013). The Standing Rock Sioux created a pan-Indian movement not seen in sixty years and galvanized a nation because the company chose a "fast track" regulatory approach that abbreviated the environmental impact statement process and short-changed the tribal consultation that should have been routine (Kent and Preister 2016a).

These examples point to the dramatically-changing social realities of doing business at the global scale. There has been a quickening around the world of citizens, with or without government and corporate assistance, taking action to protect the quality and safety of their local environment. This global trend we call Geographic Democracy and we have been tracking it for over twenty-five years. Simply put, people more than ever want to be included in decisions that affect them. For projects to succeed these days, citizens within an impacted community must become engaged in the process from the early stages of planning through its implementation.

Geographic democracy has been especially apparent in the right-ofway, infrastructure and oil and gas industries. With many larger scale projects dotting the landscapes, these three sectors often work together. Oil and gas companies have the control and the investors, infrastructure companies design and manage construction, and right-of-way professionals work with landowners to obtain easement agreements, with or without the use of eminent domain.

The pace of geographic democracy in the last few years has accelerated, as shown by the increased level of public resistance to infrastructure projects. While Keystone XL took four years to reach disruption, the Dakota Access Pipeline became a hot button issue almost overnight (Kent and Preister 2016a). What we are seeing is that the pipelines and power corridor projects, so called "linear" projects, now become nationalized, making it more difficult for companies to solve issues locally where their impacts are most felt. Moreover, this new era has generated national opposition groups whose sole purpose is to say no to any and all infrastructure projects. These are all new developments.

Our company was drawn to these sectors because of the enormous impacts they are creating in society and in witness to the strong citizen resistance they are experiencing. We got to know officials from the International Right of Way Association (IRWA), Inc., the leading global organization of nearly 10,000 engineers, right-of-way and infrastructure professionals. IRWA is a nonprofit membership organization which offers training and certification in the technical, legal, and political contexts of project development. We began attending their annual conferences and presenting two-hour sessions on Social Ecology as an antidote to typical public relations approaches. These events became well-attended and we 
began to have a following because people appreciated our message. Our company president wrote 27 articles in the last five years in the IRWA magazine with a regular column entitled, "Social Ecology: the Science of Community," some of which are cited here. Our article on Standing Rock Sioux made their cover story in December, 2016 (Kent and Preister 2016b). In an unprecedented move, the 27 columns we wrote for them to date were published as a separate anthology by IRWA and made available to members. Figure Four below shows the two models for project development that has been shown to good effect to industry insiders. It compares the traditional, intrusive approach in this industry with a social ecology approach of absorption.

\section{OLD MODEL--Ineffective}
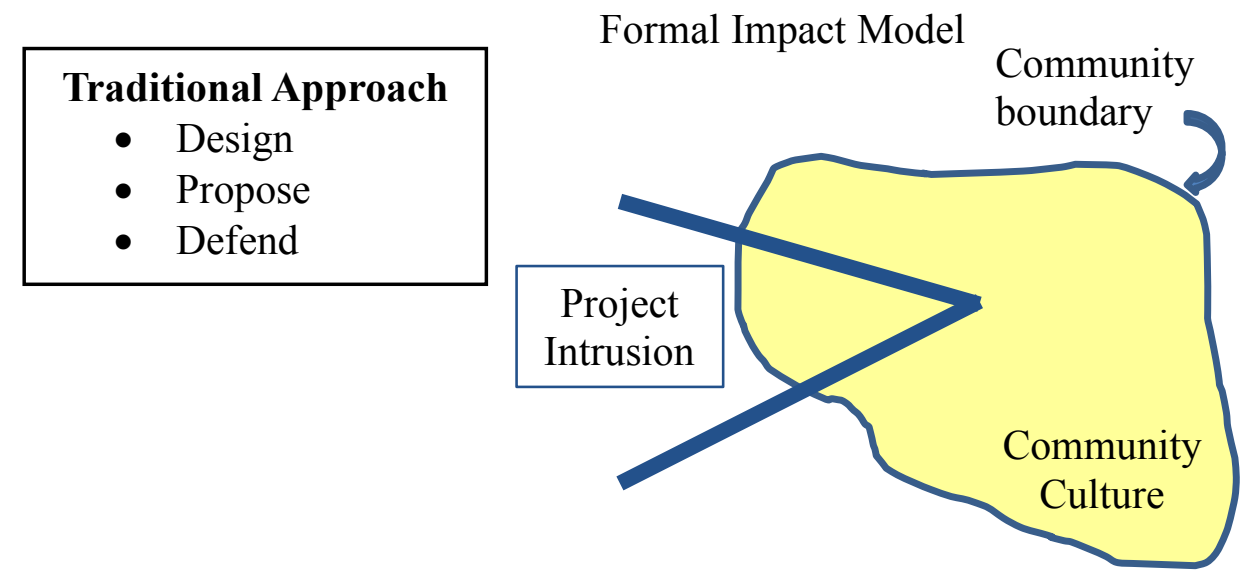

\section{NEW MODEL--Effective}

Informal Absorption Model

\begin{tabular}{|ll|}
\hline \multicolumn{2}{|c|}{ Social Ecology Approach } \\
- \\
- Eearn \\
- Engage \\
Benefit \\
\hline
\end{tabular}

C 2017 CSEPP, Inc., all rights reserved

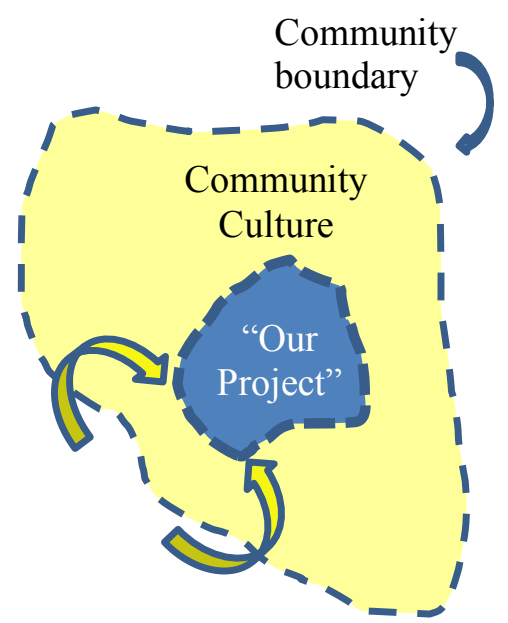

Figure 4: Ineffective and Effective Models of Project Development 
The world of infrastructure projects tends to be well-insulated with an overpopulation of attorneys, internal conferences that reinforce world views within the industry, and a generally friendly regulatory environment. This is an industry dominated by engineers with the reputation of drawing the straightest line from A to B, even if it means through the Sandhills and over the Ogallala Aquifer, as in the case of Keystone XL. Company personnel that have routine contact with impacted communities, such as right-of-way agents, have no ready avenue to bring their knowledge of community interests to the design process. Public affairs efforts are generally oriented to one-way communication and pre-occupation with information sheets. I have heard many executives say something like, "If they only had more of the facts they would like the project." Public affairs offices tend to subscribe to the "last man standing" approach in which if company officials withstand disruptive public meetings, they have higher status in their field.

It is easy to see that companies engage in behaviors that increase their social risk and they have little capacity at present for alternative approaches. These are the behaviors that we observe:

- Reluctance to invest in real citizen engagement

- Arbitrary/unrealistic project timelines that don't match community timelines

- Over reliance on the power of facts

- Under reliance on the power of trust

- Failure to incorporate local knowledge

- Misplaced reliance on organizations, officials and stakeholders, rather than citizens who are oriented to the survival and care of their communities

- The proliferation of sub-contractors which fragments communication and coordination ("I never get a call back").

IRWA invited us to develop a training course for its members. A two-day course which involved concept development and practice in community fieldwork was held in Pablo, Montana for a highway project in 2014. A follow-up pilot was held in Caro, Michigan in 2015 for Consumers Energy, the largest utility in Michigan, which was experiencing citizen issues as they expanded into wind energy. As Caro participants practiced community fieldwork, bringing their observations and stories back to the training session, we assisted them to build a more systematic understanding of the local community. Fieldwork revealed that the company has good standing among wide segments of the local population. Local business people and residents provided compliments like, "The roads are better than before," and "They kept their word." For example, this area is just south of Lake Erie and farmers have enormous drainage issues for which they install "drain tiles." Installation of wind turbines often results in the breakage of 
these drain tiles and farmers expressed surprise and pleasure that the company worked with them effectively and speedily to replace them.

During the community fieldwork exercise, one participant went to the bowling alley because it was the best place in town for lunch. He found two business owners of long-standing families, one who owned a local restaurant and the other who owned a farm-supply store. These men had two issues about newly-developing wind power: 1) "In 15 years, what will the turbines look like and what happens when their life is finished?" and, 2) "Yes, farmers are paid for their impacts but what about the neighbors? What about people who have the visual impacts but don't get paid?"

In our management framework, these are "emerging issues" and they are generally the easiest and least costly to resolve. Emerging issues are often framed as curiosity in the form of questions. The person who discovered the issues had the responsibility to provide a company response to these gentlemen within 24 hours, also a good move.

Because the training involved a single company, the second day could be devoted to internal operations. It was learned that community contact and the company message was controlled by the Public Affairs Office which expressed concern that the company message was consistent and local contact was controlled. How was the company going to track information it learns through community fieldwork and to ensure timely response to citizen issues? The question was whether the company was going to encourage all employees to be the eyes and ears of the company or if citizen contact would be relegated to one or two individuals. Thankfully, they risked choosing the former and we helped them develop procedures for early issue identification and response. This is a good example of how anthropologists assist internal operations of companies as they develop capacity for issue management.

Beginning early in 2017, IRWA listed Course 225, "Social Ecology: Listening to Community" as a required course for its certification program. Certification is the primary motivation of professionals to join IRWA. Our phones began ringing and we now have training courses scheduled in Oakland, Niagara Falls, Phoenix and Concord, New Hampshire, with courses pending in Portland, Oregon and Mexico City. As a required course, we will now have up to 10,000 members participate in this program over the next several years.

This case example is illustrative of promoting paradigm change within an industry from the inside out, what I would call "culture-based management." The author also worked for and with the Bureau of Land Management (BLM) for over thirty years in what can fairly be called a paradigm change to move the agency out of the political gridlock of the 1990s to a point of developing capacity for effective citizen engagement and issue management (Preister and Kent 1997). 


\section{Conclusions}

In this paper, I have provided concepts by which ethnography can be shaped to a management framework, and I have described case examples that show three phases to influence the corporate world-community assessment, issue management, and ethnographic training programs.

It is worth pointing out that the Social Ecology model presented here is endogenous-it emerged from anthropological practice and does not represent an effort to import trending theories from elsewhere. The strength of this article is the confirmation that anthropologists have the resources to be effective at the managerial and policy levels. In a world of rapid social change, a process that includes genuine contact with citizens in their own social and geographic context and provides a means by which project impacts can be minimized and benefits enhanced has high value. As corporations and governments experience geographic democracy in full bloom, they are recognizing that while they may have legal authority to implement their projects, without a "social license to operate" they are not able to move forward.

This development allows the further professionalization of anthropology so the day will come that it is routine practice to call upon anthropologists to design projects with local community residents and not for them or to them. Indeed, as the specialty of business anthropology grows, the concept of "co-creation" has been gaining in methodological sophistication, practical use, and legitimacy (Greenhalgh 2016). These innovations point to a robust future for business anthropology.

\section{References}

Freire, P., 1970 Pedagogy of the Oppressed. New York: Seabury Press.

Greenhalgh, T., C. Jackson, S. Shaw, T. Janamian, 2016 'Achieving research impact through co-creation in community-based health services:

literature review and case study', Milbank Quarterly, June; 94(2): 392429. Published online 2016 June 6. doi: 10.1111/1468-0009.12197.

Hunka, C., J.A. Kent, K.Preister, 1997 'Culture, strategies and community empowerment at the EPA Smuggler Superfund Site, Aspen, Colorado: a case for understanding the impact of oral communication networks and pathways on informal decision making systems.' In U.S. EPA (ed.) Community culture and the environment: A guide to understanding a sense of place, 2002, (EPA 842-B-01-003), Office of Water, Washington, D.C.

Kent J. A. 2014 'Was John Steinbeck the first social ecologist?', SteinbeckNow.com, Available at: http://www.steinbecknow.com/?s=was+john+steinbeck+the+first+social +ecologist. 
Kent J. A. and K. Preister 1999 'Methods for the development of human geographic boundaries and their uses', in partial completion of Cooperative Agreement No. 1422-P850-A8-0015 between James Kent Associates and the U.S. Department of the Interior, Bureau of Land Management (BLM), Task Order No. 001. Available at: http://www.jkagroup.com/Docs/IKent MethodsfortheDevelopment.pdf.

Kent J.A. and K. Preister 2011 'Climate change and the language of geographic place,' In Karl, H.A., P. L. Scarlett, J. V. Moreno, M. Flaxman (eds.), Restoring and sustaining lands-coordinating science, politics, and community for action, pp. 421-442. Springer Publications: New York. Available at: http://www.jkagroup.com/Docs/Climate-Change-and-theLanguage-of-Geographic-Place-final-chapter.pdf.

Kent J.A. and K. Preister 2013 'A social license to operate in the $21^{\text {st }}$ century: overcoming the clash of two cultures,' Oil and Gas Facilities magazine, August, pp. 24-27.Available at: http://www.jkagroup.com/Docs/201308-A-Social-License-to-OperateOil-and-Gas-Facilities.pdf.

Kent J.A. and K. Preister 2016a 'Geographic democracy: A widespread power shift,' Right of Way_magazine, September/October by the International Right of Way Association (IRWA), pp. 13-15. Available at: http://www.jkagroup.com/Docs/IRWA-20160729-GeographicDemocracy.pdf.

Kent J.A. and K. Preister 2016b'Beyond the permitting: the Standing Rock Sioux bring community engagement to the forefront,' Right of Way. magazine, November/December by the International Right of Way Association (IRWA), pp. 2-6. Available at: http://www.jkagroup.com/Docs/IRWA-20161107-Standing-Rock.pdf.

Malone, T. 2007 'The social ecology of women as transformational leaders,' thesis paper submitted for the degree of Masters of Arts in Cultural Anthropology, Vermont College of Union Institute \& University Core Faculty: Loree Miltich, Ph.D. Available at: http://www.jkagroup.com/Docs/TrishMalone-Social-Ecology-of-Womenas-Transformational-Leaders.pdf.

Oldenburg, R. 1989 The great good place: cafes, coffee shops, community centers, beauty parlors, general stores, bars, hangouts and how they get you through the day. New York: Marlowe and Company.

Preister, K. 2014 'Using our field experiences to build theories of applied social change-why do we not do more?' Journal of Northwest Anthropology, Volume 48, Number 1, Spring, 2014, pp. 1-10. Available at: http://www.jkagroup.com/Docs/JONA-20140323.pdf.

Preister, K. 2010 'Public policy as empowerment through anthropological practice: beyond the research paradigm' Applied Anthropology Newsletter, pp. 24-28, February. Available at: 
http://192.163.234.187/ sfaanet/news/files/8813/7493/9951/21-

1.pdf.

Preister, K. and J. A. Kent 1997 'Social ecology: A new pathway to watershed restoration.' In J. E. Williams, M. P. Dombeck and C. A. Wood, (eds.) Watershed Restoration: Principles and Practices, Pp. 28-48.

Bethesda, Md.: The American Fisheries Society. Available at:

http://www.jkagroup.com/Docs/KPreister PathwayToWatershedRestor ation.pdf.

Preister, K. and J.A. Kent 2001 'Using social ecology to eet the productive harmony intent of the National Environmental Policy Act (NEPA)'

Hastings West-Northwest Journal of Environmental Law and Policy, Volume 7, Issue 3, Spring, pp. 235-251. Berkeley, CA.: Hastings College of the Law. Available at:

http://www.jkagroup.com/Docs/KPreister UsingSocialEcology.pdf.

Preister, K., J. Kent, J. Ryan, B. Schultz, L. Ibanez, T. Malone 2004 'A situational assessment of Two Rivers Village: Culturally-based positioning in the marketplace.' A report by James Kent Associates to Two Rivers Village, Inc.

Steinbeck, J. 1941 Log from the Sea of Cortez. New York: Penguin Books.

Kevin Preister received his doctorate in anthropology from the University of California at Davis in 1994. He has worked over 35 years in a variety of development settings ranging from recreation to energy, mineral, community and economic development, and social service delivery. He has worked extensively in natural resource decisionmaking, becoming a leader in paradigm change with the Forest Service and the Bureau of Land Management in best practices in community engagement. In recent years he was worked with the right-of-way, infrastructure and energy sectors to foster successful collaboration with communities. 